Original Article

\title{
Cardiovascular risk factors and evolution of patients attended with COVID-19 in a National
}

\section{Reference Hospital from Lima, Peru}

Germán V. Valenzuela, ${ }^{1,2}$ Alfonso J. Rodríguez-Morales, ${ }^{3,4, *}$ Roxana Mamani, ${ }^{5}$ Ricardo Ayala, ${ }^{5}$ Katherine Pérez, ${ }^{5}$ Cynthia Sarmiento, ${ }^{5}$ Jessica Calcino, ${ }^{5}$ Luis García, ${ }^{5}$ José Amado. 2,5

${ }^{1}$ Clinica Delgado, Grupo AUNA, Lima, Peru.

${ }^{2}$ Facultad de Medicina Humana, Universidad Nacional Mayor de San Marcos, Lima, Peru.

${ }^{3}$ Public Health and infection Research Group, Faculty of Health Sciences, Universidad Tecnologica de Pereira, Pereira, Risaralda, Colombia.

${ }^{4}$ Grupo de Investigacion Biomedicina, Faculty of Medicine, Fundacion Universitaria Autonoma de las Americas, Pereira, Risaralda, Colombia.

${ }^{5}$ Emergency Department, Hospital Nacional Edgardo Rebagliati Martins, EsSalud, Lima, Peru.

Words: 1,608 | Pages: 16 (limit 20 pages) | Abstract: 248 (limit 250) | Figures: 2 | Tables: 2

*Corresponding Author. Email: arodriguezm@utp.edu.co.

Running Head: COVID-19 and Cardiovascular risk factors in Peru 


\begin{abstract}
:
Objectives. Coronavirus disease 2019 (COVID-19) fatal outcomes have been associated with multiple cardiovascular risk factors. In new epidemic areas, such as Latin America, there is a lack of studies about this. Here, we evaluated those factors in a retrospective cohort of patients in a national reference hospital of Lima, Peru. Design. A retrospective cohort observational study was done. For this study, information was obtained from clinical records of the hospital for the cases that were laboratory-diagnosed and related, during March $6^{\text {th }}$ and April $30^{\text {th }}, 2020$. rRT-PCR was used for the detection of the RNA of SARS-CoV-2 following the protocol Charite, Berlin, Germany, from nasopharyngeal swabs at the National Institute of Health. Calculation of the odds ratio (OR) with the respective $95 \%$ confidence interval $(95 \% \mathrm{CI})$ was done, also logistic regression for adjusted OR (multivariate) was done. Values of $\mathrm{p}<0.05$ were considered significant for all analyses. Results. One hundred six hospitalized patients were evaluated. The mean age of patients was 61.58 years (SD 16.81). Cardiovascular risk factors among them were hypertension $(46.2 \%)$, diabetes $(28.3 \%)$, and obesity (28.3\%), among others. Fifty-six patients died (52.8\%). Mortality associated factors at the multivariate analysis were arterial hypertension $(\mathrm{OR}=1.343,95 \% 1.089-1.667)$, myocardial injury $(\mathrm{OR}=1.303,95 \% 1.031-1.642)$, and mechanical ventilation (OR 1.262, 95\% 1.034-1.665), as associated factors. Conclusion. As observed in other regions of the world, cardiovascular risk factors represent a significant and independent threat to be considered in patients with COVID-19. Further studies and interventions in Peru and Latin America are expected.
\end{abstract}

Keywords: COVID-19; SARS-CoV-2; risk factors; outcomes; cardiovascular; Latin America. 


\section{Introduction}

Coronaviruses are single-stranded positive-sense RNA viruses, with the capacity for rapid mutation and recombination. They are known to cause respiratory or intestinal infections in humans and animals. Moreover, acute respiratory infections including influenza, respiratory syncytial and bacterial pneumonia are triggers for cardiovascular diseases and, on the other hand, the underlying cardiovascular disorders are usually associated with comorbidities, which may increase tie incidence and severity of infectious diseases. ${ }^{1-3}$

Cardiovascular complications associated with the coronavirus infection were described since infections with SARS-COV and recently with SARS-COV-2. The later generate the clinical pattern defined as COVID-19, described in the first time in December 2019 in Wuhan-China. After that, there were mentioned direct effects of the virus and the consequences associated with the host immune response. ${ }^{1,4-8}$

Cardiovascular compromise in patients with COVID-19 has not been well studied because data is scarce. However, there were described cases of myocardial injury, myocarditis, thromboembolic disease, arrhythmias, among others. But there is no information about the longterm consequences of this disease ${ }^{2,9}$

Edgardo Rebagliati Martins national hospital is the largest hospital of the Peruvian social security with 2,000 hospital beds and is considered as a national reference center for patients with COVID19 and concentrate a higher quantity of severe cases associated with this clinical condition. ${ }^{19}$

The objectives of the present study are to describe the prevalence of cardiovascular risk factors in the selected population, to evaluate the clinical findings, laboratory and electrocardiographic data, and describe the evolution of patients, taking into count the presence of some cardiovascular risk factors. 


\section{Methods}

An observational, retrospective study carried out in the adult emergency service of Hospital Nacional Edgardo Rebagliati Martins- EsSalud, located in the district of Jesus María in LimaPerú. This service accounts for 180 beds and realizes 164,370 medical attentions per year and 22,883 admissions per day in patients over 14 years of age with a public health insurance system.

Patients considered for this study were those with a clinical diagnostic of COVID-19 and confirmed by molecular testing, RT-PCR, from nasopharyngeal swabs, attended and hospitalized between March $6^{\text {th }}$ and April $30^{\text {th }}$ in the Hospital Rebagliati. Only patients with confirmed pulmonary lesions by CT scan and oxygen saturation level below $93 \%$ were hospitalized due to a higher demand for health care services in Peruvian public hospitals. There were excluded patients transferred to other health centers and patients that arrive without vital signs.

Data from an electronic clinical record of patients was obtained, identifying clinical and laboratory variables, and their evolution during hospitalization. A twelve-lead ECG was recorded too. We used SPSS 24.0 for statistical analysis that includes descriptive, bivariate analysis, and multivariate analysis (binary logistic regression). A p-value of less than 0.05 was considered statistically significant.

The project was authorized for the emergency department and the Ethics and investigation committee for COVID-19 in EsSalud (study approval number: 83328). The principle of confidentiality was guaranteed. Informed consent was not obtained because the source document was secondary (an electronic clinical record), and there was not any intervention for the patient.

\section{Results}

One hundred six hospitalized patients were evaluated. The mean age of patients was 61.58 years (SD 16.81), 47 (44.34\%) had more than 65 years of age, 81 (76.4\%) were of male gender (Table 1). Cardiovascular risk factors among the study population were hypertension (46.2\%), diabetes 
(28.3\%), and obesity (28.3\%). Sixteen patients $(6.76 \%)$ report a previous cardiovascular disease $(15.09 \%)$.

They arrived in the emergency room with more than seven days of symptoms: 7.35 (SD 3.53). Thirty-two cases (30.18\%) had symptoms between 3 and 7 days and $54.71 \%$ with more than seven days.

The most frequent signs and symptoms during emergency arrival (Figure 1) were dyspnea $(82.07 \%)$, tachycardia (35.8\%), and higher levels of blood pressure (17.9\%), defined as levels over $140 \mathrm{mmHg}$ of systolic or levels over $90 \mathrm{mmHg}$ of diastolic pressure.

Troponin $\mathrm{T}$ values higher than $99^{\text {th }}$ percentile of superior reference limit, suggestive of myocardial injury was found in 40 of 79 patients tested (50.6\%). The median value was 0.033 (IQR 0.047).

In 40 patients, 12-lead ECG recorded was obtained. 22 (55\%) had an ECG without specific alterations. In 11 cases $(27.5 \%)$ there were rhythm alterations (atrial fibrillation, 4 cases; sinus bradycardia, 2 cases; sinus tachycardia, 1 case; $3^{\text {rd }}$ degree A-V block 1 case; $1^{\text {st }}$ degree A-V block 2 cases; and ventricular extrasystoles, 1 case) in 4 cases (10\%) left ventricular hypertrophy and in 3 cases (7.5\%) findings that suggest acute ischemia (ST elevation in 1 case and ST depression in 2 cases).

The median of hospitalization was eight days (IQR 12.25). In $64.15 \%$ of cases, the time of admission was higher than seven days, and in 17 patients (16.04\%) was more top than 30 days. $22(20.75 \%)$ patients entered to invasive mechanical ventilation.

Fifty-six patients died, which corresponds to a mortality rate of $52.8 \%$ (Figure 1). Mortality associated factors (Table 2) were age more than 65 years, myocardial injury, mechanical ventilation, and arterial hypertension were associated with statistical differences in bivariate 
analysis. In the multivariate analysis, we found arterial hypertension, myocardial injury, and mechanical ventilation as associated factors (Table 2).

\section{Discussion}

The present report describes cardiovascular risk factors and some clinical, laboratory, and electrocardiography findings in a group of patients hospitalized for moderate to severe COVID19 attended in a national reference hospital of social security.

Although multiple studies have reported the clinical findings in COVID-19, ${ }^{20-27}$ and some of the associated risk factors, ${ }^{25,26}$ few in Latin America have shown the relationship between cardiovascular risk factors and fatal outcomes. ${ }^{26}$

The prevalence of cardiovascular risk factors was similar to CDC and Italian reports (from the Lombardy region) for arterial hypertension (46.2\%) and higher in comparison with reports of Chinese hospitals (30.5\%). A similar phenomenon occurs for diabetes found in $28.3 \%$, which was identical to the CDC report and superior to Italian and Chinese reports, $17.3 \%$ and $14 \%$ respectively ${ }^{3,5,6,16}$ But, the prevalence of cardiovascular risk factors and previous cardiovascular disease is higher in patients with severe COVID-19 and in patients who died due to COVID-19. ${ }^{21}$

However, these prevalences in hospitalized patients with COVID-19 were superior to the Peruvian TORNASOL report, which corresponds to a national evaluation for hypertension and other cardiovascular risk factors, carried out in 2011, where a prevalence of $27.3 \%$ was found. ${ }^{13}$ At the national level, the prevalence of Diabetes in Peru was reported in ranges between 5 and $7 \% .^{14}$

Hypertension and cardiovascular disease were associated with a higher risk of severity and mortality in patients infected with COVID-19 because their conditions could damage the vascular structure, and it is more likely to develop into critical disease during the infection. Moreover, 
patients with chronic cardiovascular disease are more likely to be infected due to their weakened heart function and low immunity, developing severe disease patterns. ${ }^{20-22}$

Recent studies indicate multi-organ tropism of SARS-CoV-2, including heart, vascular system, and the circulation, which is speculated to influence the course of the disease as well as aggravate preexisting conditions. The increased-myocardial expression of ACE2 in patients with cardiovascular disease and COVID-19 has been suggested as a possible mechanism of myocardial cell invasion and injury levels to worse outcomes. ${ }^{21}$

Myocardial injury is manifested as an elevation of troponin levels above the $99^{\text {th }}$ percentile of superior normality level and is associated with an increase in mortality. It could be presented with electrocardiographic and echocardiographic changes. In some cases, could evolution to a fulminant myocarditis $1,2,6,15$

We found a prevalence of myocardial injury of 50.6\%, superior to report in the hospitalized population (7-17\%), and ICU population (22-31\%) $)^{1,12,15}$. Moreover, in a recent metanalysis of 26 clinical studies with 11,685 patients, the prevalence was $20 \% \cdot{ }^{17}$ However in subpopulations of severe or critical COVID-19 cases, similar to the cases described in this report, the prevalence could be much higher: from $65.2 \%$ and $80 \% .^{21}$

In a retrospective study of 191 patients, older age was recognized as a risk factor of mortality and has been reported as a significant predictor of mortality in SARS and MERS, probably because of age-dependent defects in T-cell and B-cell function and the excess production of type 2 cytokines that could amplify viral replication and prologs proinflammatory responses. ${ }^{23}$ Other factors like the presence of comorbidities in older patients (particularly hypertension) are believed to be risk factors for severe disease and death for SARS-Cov-2 infection. 
Moreover, in deceased patients, higher levels of cardiac troponins were associated with poorer outcomes and mortality, as was described in several reports. ${ }^{16,24}$ In a recent study in Bolivia, the mortality rate was $5.6 \%$, but age and hypertension ( $\mathrm{OR}=3.284,95 \% \mathrm{CI} 1.276-6.291)$ were the main associated factors with the fatal outcomes, very similar to our current findings for this factor (Table 2). ${ }^{26}$

Previously a preliminary description of patients with severe COVID-19 was reported in our hospital. This study described 17 patients, 5 of them died. Authors identified advanced age (6), arterial hypertension (4), and obesity (3), as the main observed risk factors in these patients. ${ }^{27}$ This study is an exploratory case-series without randomization, that obtain data from electronic clinical reports. We did not register body mass index, and there was not a formal criterion to get troponin dosage or ECG recording in every patient hospitalized for COVID-19. Although there is an essential number of patients in this region, and describe the cardiovascular findings associated with this disease.

\section{Conclusions}

There is a high prevalence of cardiovascular risk factors in our patients with severe COVID-19 disease. Dyspnea, tachycardia, and a higher level of blood pressure at admission were the most frequent clinical manifestations. We found myocardial injury in almost half of the total population and ECG changes in more than a fourth of our population. On the other hand, arterial hypertension, the use of mechanical ventilation, and myocardial injury were associated with higher mortality in our patients.

\section{Acknowledgments}

None.

\section{Conflict of Interests}

None. 


\section{References}

1. Madjid M, Safavi-Naeini P, Solomon SD, Vardeny D. Potential effect of coronaviruses on the Cardiovascular System. JAMA Cardiol. doi:10.1001/jamacardio.2020.1286

2. Akhmerov A, Marbán E. COVID, and the Heart. Circulation Research. DOI:10.1161/CIRCRESAHA.120.317055

3. Li B, Yang J, Zhao F, Zhi L, Wang X, Liu L, Bi Z, et al. Prevalence and impact of cardiovascular metabolic diseases on COVID-19 in China. Clinical Research in Cardiology. https://doi.org.10.1007/s00392-020

4. Rizzo P, Vieceli Dalla Sega F, Fortini F, Marrocino L, Rapezzi G, Ferrari R. COVID-19 in the heart and the lungs: Could we "Notch" the inflammatory storm? Basic Research in Cardiology. https//doi.org.10.1007/s00395-020-0791-5

5. Guo T, Fan Y, Chen M, Wu X, Zhang L, He T, Wang H, et al. Cardiovascular Implications of Fatal Outcomes of Patients with Coronavirus Disease 2019 (COVID-19). JAMA Cardiol. doi: 10.1001/jamaardio.2020.1017

6. Shi S, Qin M, Shen B, Cai Y, Liu T, Yang F, Gang W, et al. Association of Cardiac Injury with Mortality in Hospitalized Patients with COVID-19 in Wuhan, China. JAMA Cardiol. doi:10.1001/jamacardio.2020.0950

7. Wu Z, McGoogan JM. Characteristics of and Important Lessons From the Coronavirus Disease 2019 (COVID-19) Outbreak in China Summary of a Report of 72314 Cases From the Chinese Center for Disease Control and Prevention. JAMA. 2020. doi: 10.1001/jama.2020.2648.

8. Yang J, et al. Prevalence of comorbidities in the novel Wuhan coronavirus (COVID-19) infection: a systematic review and meta-analysis. Prevalence of comorbidities in the novel Wuhan coronavirus (COVID-19) infection: a systematic review and meta-analysis. Int J Infect Dis. 2020. pii: S1201-9712(20)30136-3. doi: 10.1016/j.ijid.2020.03.017.

9. Bansal M. Cardiovascular disease and COVID-19. Diabetes \& Metabolic Syndrome: Clinical Research \& Reviews 2020;14:247-50 
10. Ammirati E, Wen Wang D. SARS-CoV-2 inflames the heart. The importance of awareness of myocardial injury in COVID-19 patients. International Journal of Cardiology. https://doi.org/10.1016/j.jicard.2020.03.086

11. Han H, Xie L, Liu R, Yang J, Liu F, Wu K, Chen L, et al. Analysis of heart injury laboratory parameters in 273 COVID-19 patients in one hospital in Wuhan, China. J Med VIrol. 2020;1-5

12. Parankpe I, Russak AJ, De Freitas JK, Lala A, Motto R, Vaid A, et al. Clinical Characteristics of Hospitalized COVID-19 Patients in New York City. MedRxiv. 2020 apr 23. doi: 10.1101/2020.04.19.20062117 [Epub ahead of print]

13. Segura-Vega L, Agusti C, Ruiz-Mori E. Factores de Riesgo de las Enfermedades Cardiovasculares en el Perú II. Revista Peruana de Cardiología. Enero-Abril 2013;39(1):5-59

14. Carrillo-Larco RM, Bernabé-Ortiz A. Diabetes mellitus tipo 2 en Perú: una revisión sistemática sobre la prevalencia e incidencia en población general. Rev Peru Med Exp Salud Publica. 2019;36(1):26-36

15. Long B, Brady WJ, Koyfman A, Gottlieb M. Cardiovascular complications in COVID-19. Am J Emerg Med. 2020;S0735-6757(20)30277-1. doi:10.1016/j.ajem.2020.04.048

16. Kang Y, Chen R, Mui D, Ferrari V, Jagasia D, Scherrer-Crosbie M, et al. Cardiovascular manifestations and treatment considerations in covid-19. Heart 2020;0:1-10. doi:10.1136/heartjnl-2020-317056

17. Bavishi C, Bonow O, Trivedi V, Abbott D, Messerli FH, Bhatt DL. Acute Myocardial Injury in patients Hospitalized with COVID-19 Infection: A Review. Progress in Cardiovascular Diseases. https://doi.org/10.1016/j.pcad.2020.05.013

18. Atri D, Siddiqi HK, Lang JP, Nauffal V, Morrow DA, Bohula EA. COVID-19 for the Cardiologist: Basic Virology, Epidemiology and Cardiac Manifestations, and Potential Therapeutic Strategies. JACC Basic to Translational Science. https://doi.org/10.1016/j.jacbts.2020.04.002

19. Vásquez Alva R, Amado Tineo J, Ramírez Calderón F, Velásquez Velásquez R, Huari Pastrana R. Sobredemanda de atención médica en el servicio de emergencia de adultos de un 
hospital terciario, Lima, Perú. An Fac Med. 2016; 77(4):379-384. DOI: 10.15381/anales.v77i4.12654

20. Zheng Z., Peng F., Xu B., Zhao J., Liu H., Peng J., et al. Risk factors of critical \& mortal COVID-19 cases: a systematic literature review and meta-analysis. J. Infect. 2020 Apr 23. pii: S0163-4453(20)30234-6. doi: 10.1016/j.jinf.2020.04.021.

21. Lazaridis C, Vlachogiannis NI, Bakogiannis C, Spyridopoulos I, Stametelopoulos K, Kanakakis I, et al. Involvement of Cardiovascular System As the Critical Part in Coronavirus Disease 2019 (COVID-19) Prognosis and Recovery. Hellenic J Cardiol. 2020 Jun 10 doi: 10.1016/j.hjc.2020.05.004

22. Zhang X, Yu J, Pan Ly, Jiang Hy. ACEI/ARB use and risk of infection or severity or mortality of COVID-19. A systematic review and meta-analysis. Pharmacological Research 2020;158:104927 doi: 10.1016/j.phrs.2020.104927

23. Zhou F, Yu T, Fan G, Liu Y, Liu Z, Xiang J, et al . Clinical course and risk factors for mortality of adults inpatients with COVID-19 in Wuhan, China: a retrospective cohort study. Lancet 2020;395:1054-62

24. Chen T, Wu D, Chen Hm Yan W, Yang D, Chen G, Ma K. Clinical characteristics of 113 deceased patients with coronavirus disease 2019: retrospective study. BMJ 2020;368:m1091 doi:10.1136/bmj/m1091

25. Rodriguez-Morales AJ, Cardona-Ospina JA, Gutiérrez-Ocampo E, Villamizar-Peña R, Holguin-Rivera Y, Escalera-Antezana JP, Alvarado-Arnez LE, Bonilla-Aldana DK, FrancoParedes C, Henao-Martinez AF, Paniz-Mondolfi A, Lagos-Grisales GJ, Ramírez-Vallejo E, Suárez JA, Zambrano LI, Villamil-Gómez WE, Balbin-Ramon GJ, Rabaan AA, Harapan H, Dhama K, Nishiura H, Kataoka H, Ahmad T, Sah R. Clinical, laboratory and imaging features of COVID-19: A systematic review and meta-analysis. Travel Med Infect Dis. 2020;34:101623.

26. Escalera-Antezana JP, Lizon-Ferrufino NF, Maldonado-Alanoca A, Alarcón-De-la-Vega G, Alvarado-Arnez LE, Balderrama-Saavedra MA, Bonilla-Aldana DK, Rodríguez-Morales AJ, on behalf of LANCOVID. Risk Factors for Mortality in Patients with Coronavirus Disease 2019 
(COVID-19) in Bolivia: An Analysis of the First 107 Confirmed Cases. Infez Med 2020; 28(2):238-242.

27. Acosta G, Escobar G, Bernaola G, Alfaro J, Taype W, Marcos C, et al. Caracterización de pacientes con COVID-19 grave atendidos en un hospital de referencia nacional del Perú. Rev Peru Med Exp Salud Publica. 2020;37(2). doi: https://doi.org/10.17843/rpmesp.2020.372.5437 
Table 1. Clinical and demographical features of the patients with COVID-19.

\begin{tabular}{lll}
\hline Variable & N & \% \\
\hline Age distribution & 3 & 2.83 \\
$<30$ years & 56 & 52.83 \\
$30-64$ years & 39 & 36.79 \\
$65-84$ years & 8 & 7.55 \\
$\geq 85$ years & & \\
Gender distribution & 81 & 76.4 \\
Male & 25 & 23.6 \\
Female & & \\
Cardiovascular risk factors & 49 & 46.2 \\
Hypertension & 30 & 28.3 \\
Diabetes & 30 & 28.3 \\
Obesity & 16 & 15.1 \\
Previous history of cardiovascular disease & & \\
\hline
\end{tabular}


Table 2. Mortality associated factors.

\begin{tabular}{lcccc}
\hline \multicolumn{1}{c}{ Variable } & $\mathbf{O R}_{\mathbf{c}}$ & $\mathbf{9 5 \%} \mathbf{C I}$ & $\mathbf{O R}_{\mathbf{a}}$ & $\mathbf{9 5 \%} \mathbf{C I}$ \\
\hline Arterial hypertension & 4.280 & $1.880-9.730$ & 1.343 & $1.089-1.667$ \\
Myocardial injury & 4.700 & $1.810-12.210$ & 1.303 & $1.031-1.642$ \\
Mechanical ventilation & 5.440 & $1.690-17.470$ & 1.262 & $1.034-1.665$ \\
Age more than 65 years & 2.760 & $1.220-6.200$ & 1.070 & $0.848-1.354$ \\
Obesity & 1.240 & $0.520-2.900$ & 1.055 & $0.848-1.323$ \\
Male gender & 1.590 & $0.640-3.920$ & 0.959 & $0.747-1.217$ \\
Diabetes & 0.850 & $0.360-1.980$ & 0.879 & $0.691-1.097$ \\
\hline
\end{tabular}

$\mathrm{OR}_{\mathrm{c}}=$ crude odds ratio (bivariate analysis); $\mathrm{OR}_{\mathrm{a}}=$ adjusted odds ratio (multivariate analysis). 
Figure 1. Clinical findings at the ER income.

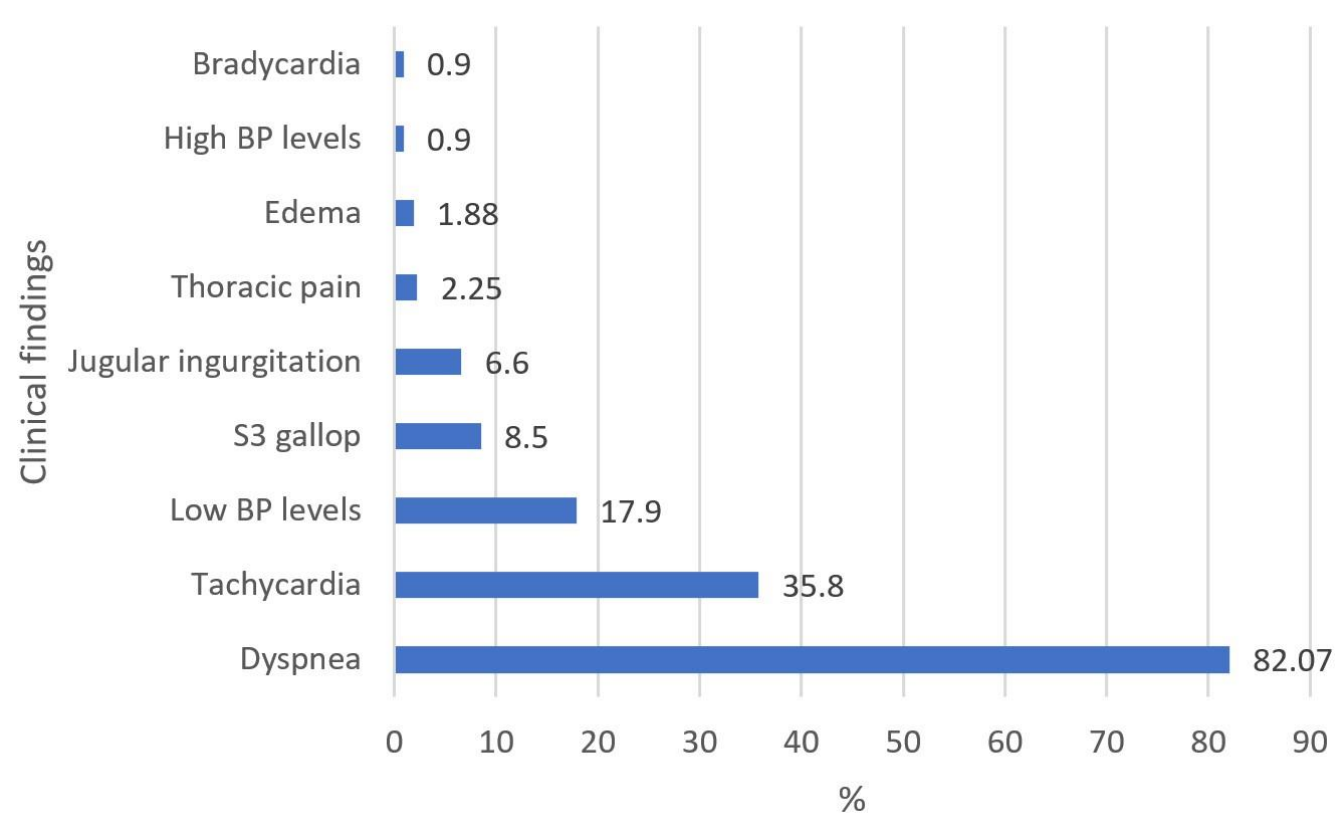


Figure 2. Survival rates of the patients by time.

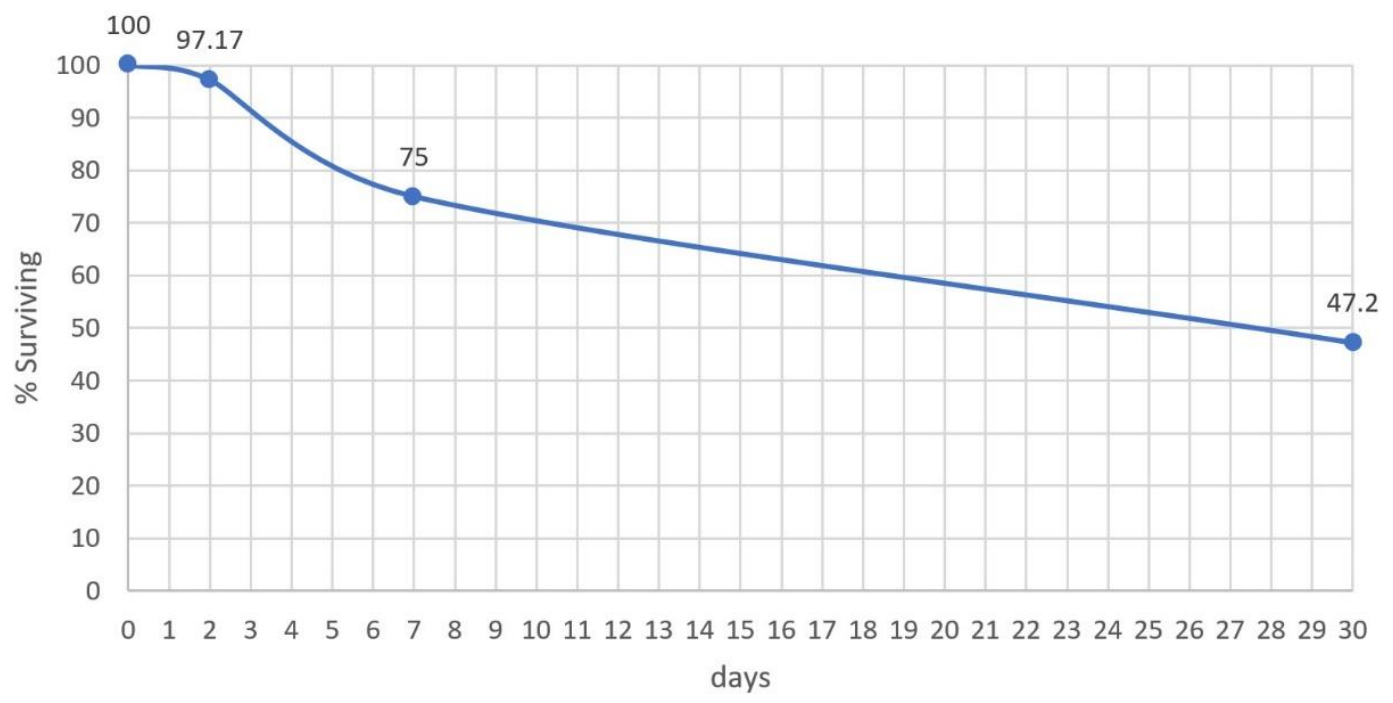

